\title{
Trabajadores migrantes en tierra propia. Población maya y mercado de trabajo en Chetumal, Quintana Roo
}

\author{
Ligia Aurora Sierra Sosa \\ UNIVERSIDAD DE QuintaNa ROO, ChETUMal
}

La población maya de la ciudad de Chetumal, Quintana Roo, aún mantiene fuertes patrones culturales de su matriz original, en especial la lengua. Su procedencia y exposición a la ciudad, ha suscitado y originado en ella diferencias de posición social y económica. Se ha observado que la migración interpeninsular refuerza los patrones culturales, y que las desigualdades entre los mayas y los no mayas, obedecen a la distribución desigual de los beneficios en términos de ingreso, educación y otros.

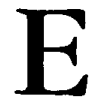
1 objetivo del presente trabajo es analizar, con el apoyo de recursos metodológicos cuantitativos (encuesta) y cualitativos (información acerca de las trayectorias laborales), las condiciones de reproducción de la fuerza de trabajo indígena maya y su absorción en el mercado laboral que ofrece la ciudad de Chetumal, Quintana Roo, en la actualidad. Como parte de este estudio se identificarán las características étnicas mayas, como son la lengua, el vestido, la vivienda y las costumbres y ritos, entre otras. ${ }^{1}$

${ }^{1}$ Los datos estadísticos que empleamos pro-
Además, se integrarán al mismo los diferentes rubros que definen el mercado de trabajo, como son: los ramos de actividad, el tipo de ésta, la ocupación o categoría ocupacional y el ingreso. Creemos que la presente inves-

vienen de la sistematización de la encuesta denominada Encuesta Socieconómica y de los Grupos Étnicos de Chetumal (ESOYGeCH), aplicada en 1993 como parte de las investigaciones sociales que realizaba el Centro de Investigaciones de Quintana Roo (CIQRo). Ésta reúne información de 393 jefes de familia. La distribución de los jefes de familia elegidos surgió de un proceso riguroso de sectorización del croquis urbano y abarcó todos los espacios ocupados de la ciudad. La muestra se obtuvo a 
tigación es pertinente por la escasa atención que han otorgado los estudios sociales a este fenómeno y a la población indígena contemporánea y fronteriza en las ciudades de Quintana Roo y, en general, en la península de Yucatán. ${ }^{2}$

Como aspecto esencial para la comprensión de los rasgos que definen y caracterizan a la población indígena maya en la capital del estado de Quintana Roo, presentaremos en la primera parte una visión acerca de su procedencia y de su comportamiento demográfico. No está de más precisar que el vehículo principal, aunque no único, que hemos tomado como referente étnico, es la lengua maya; ello nos permitió acercarnos al examen de la permanencia de la población indígena en el ámbito urbano. Se sabe que la mezcla entre el idioma maya y el español

partir del total de viviendas (22 064) de la ciu$\mathrm{dad}$, lo que corresponde a un nivel de significación de $5 \%$. El diseño del instrumento partió de los indicadores generales de población y se concretizó en aspectos relacionados con las características mayas y el mercado de trabajo. Por un lado, el método cuantitativo nos proporcionó datos y correlaciones significativas, sin embargo se recurrió al método cualitativo para dar respaldo narrativo y vivo a los datos.

${ }^{2}$ En el estado de Yucatán se han realizado investigaciones fundamentalmente sobre el campesinado en el área rural. Puede verse al respecto a Baños, "Reconfiguración", 1993; y a Hervik, "Social", 1994. Además existen otros trabajos urbanísticos que abordan temáticas sobre costumbres e integración cultural en la ciudad de Mérida. En la región centro del estado de Quintana Roo se han realizado trabajos en el área rural del municipio de Felipe Carrillo Puerto, en especial sobre la reproducción social de la unidad doméstica; puede consultarse a Hostettler, "Transformaciones", 1992. crece día con día, pues se trata de una relación indisoluble que se reafirma tanto en la convivencia social, como en los diversos espacios institucionales estatales o privados. Se considera que, en la península de Yucatán, la lengua maya continúa siendo un importante instrumento de comunicación en las relaciones familiares, sociales $y$, hasta cierto punto, laborales; es decir, su uso cotidiano aún es frecuente en una población indígena demográficamente importante que habita a lo largo y a lo ancho de la península.

\section{EL USO DE LA LENGUA MAYA}

En Quintana Roo, la población indígena y su lengua se encuentran dominados por los patrones culturales que se difunden a través del español. Como ocurre en diversas regiones del país, los grupos que hablan lenguas diferentes a éste, han padecido y padecen agresiones derivadas de la estructura social y de la ideología dominante. A esta hostilidad deben sumarse las campañas de alfabetización y bilingüismo, impulsadas por algunas escuelas estatales, programas federales y medios de comunicación, que más bien parecen ser mecanismos expresos de castellanización. ${ }^{3}$ Las pre-

${ }^{3}$ El programa federal del Consejo Nacional de Fomento Educativo (CONAFE), al impulsar la alfabetización y educación formal de la población indígena y no indígena que vive en zonas marginadas y alejadas en donde la SEP no llega (educación formalizada a nivel preescolar y primaria), busca integrar a los marginados a la modernidad económica y a las demandas sociales. Cierto que sus instrumentos y medios 
siones sociales y económicas de la sociedad de mercado que en la actualidad prevalece, motiva constantemente a la población indígena a prescindir de su ámbito sociocultural a cambio de integrarse al desarrollo, a la civilización o modernización, provocando este proceso la pérdida progresiva (o la desvaloración) de su propia identidad. ${ }^{4}$

La lengua es uno de los elementos que, tradicionalmente, han tomado los censos oficiales para identificar a grupos indígenas. Ello, por sí mismo, reafirma el hecho de que ésta es un indicador de suma importancia. Sabemos que la lengua propia o aprendida en la unidad doméstica ocupa el centro de la vida cotidiana, es regu-

son escasos, sin embargo, su permanencia a través de los instructores comunitarios hace posible su regular funcionamiento. Es evidente que la educación que esta institución se plantea pretende enlazar y recuperar el conocimiento primario de los niños para que, a partir de él, se dé la castellanización. Es decir, la lengua indígena y la cultura local son utilizadas como un escalón para acceder a la castellanización y a su eventual integración nacional. Sobre el particular se puede consultar de manera general sobre las estrategias de homogeneidad que el gobierno ha aplicado a la población indígena, así como la propuesta para el reconocimiento pluriétnico de México, el libro de Bonfil, México, 1994. Respecto a la presencia cotidiana de la lengua maya, su importancia aun en el ámbito urbano y su relación con el español, puede verse a Ligorred, "Conquista", 1994, p. 8.

" Para Roberto Cardoso de Oliveira, "entre las presiones disgregadoras que más eficazmente afectan a los grupos indígenas en contacto sistemático con la sociedad nacional, estarían las que inciden directamente en sus contingentes infantiles", tan es así que les crea una conciencia negativa de sí mismos. Cardoso, $E t$ nicidad, 1992. p. 33. ladora de la identidad étnica, lo que guía su funcionamiento; la lengua conduce al manejo simbólico y es el medio por excelencia de expresión y comunicación. En el análisis de la lengua maya yucateca, se ha señalado que ésta se encuentra en la categoría de lengua viva y/o en resistencia. ${ }^{5}$

Los datos obtenidos en el trabajo de campo por esta investigación, tanto en nuestra encuesta como en las entrevistas abiertas aplicadas en Chetumal, muestran sin reservas que, efectivamente, la lengua maya es una lengua viva. En nuestro estudio, como hemos mencionado, damos prioridad a los hablantes de la misma y tomamos como indicador secundario a los que la entienden, pero no la hablan. Del total de jefes de familia encuestados (393 casos) el 23.9\% (es decir 94 casos) son hablantes de esta lengua $y$, por tanto, los consideramos como población maya. Al hablar de esta población en Chetumal, tomaremos en cuenta exclusivamente estos dos últimos indicadores.

Por lo común, los espacios de la ciudad de Chetumal en los que se usa la lengua nativa son aquellos donde convergen los miembros del grupo maya, ya sea en la unidad doméstica, en el ámbito laboral, en el mercado o

\footnotetext{
${ }^{5}$ En un trabajo sobre las lenguas indígenas, Ligorred propone tres criterios para ubicar las condiciones etnolingüísticas de las mismas; éstos son $a$ ) lenguas vivas o en resistencia, $b$ ) lenguas en declinación o en peligro de extinción, y c) lenguas en obsolescencia o en vías de extinción $y$ extintas. $\mathrm{El}$ autor define el estado de conservación de las lenguas a partir del número de hablantes y de su ubicación geográfica. Véase a Ligorred, Lenguas, 1992, p. 157.
} 
en las ceremonias religiosas. Ello se puede deducir de los datos que arroja la encuesta en el concepto "lugar de preferencia del uso de la lengua maya", donde un $\mathbf{2 8 \%}$ expresó su predilección por utilizar la maya en el ámbito de la vivienda, un $18 \%$ respondió que la práctica en el campo laboral y un $9.3 \%$ en otros lugares, como son el mercado y la iglesia. Hay que destacar, sin embargo, que un $27 \%$ manifestó que emplea el habla nativa preferentemente cuando regresa a su tierra natal o de origen, lo que significa que los espacios para su uso en la ciudad de Chetumal son reducidos y que el empleo de esta lengua se considera, en cierta forma, un estigma social. ${ }^{6}$

En las relaciones interpersonales, los jefes de familia mayas hablan su lengua principalmente con los familiares mayores y su cónyuge, pero no con los hijos; también la hablan con otras personas, específicamente, con los adultos y los amigos. Esto se debe a que el grupo social y lingüísticamente dominante de la ciudad es, en su mayoría, de habla española. Por otra parte, el peso de los vecinos en el contexto de habla maya es representado por una baja participación. Se puede suponer que esto se deba a que el grupo no se desplazó a la ciudad como tal, por lo que su ubicación dependió, sobre todo, del acceso al

\footnotetext{
${ }^{6}$ Barbara Pfeiler, en su trabajo sobre la vitalidad de la lengua maya en Yucatán, distingue tres factores; estatus, demografia y apoyo institucional. Este último es para la autora el factor más marcado respecto al apoyo de las instituciones de una nación, región o comunidad para alentar el uso de la comunicación en lengua indígena. Pfeiler, "Lealtad", 1993.
}

espacio urbano o de las facilidades eventuales para establecer su vivienda, sin importar la proximidad de los parientes o amigos hablantes de la lengua maya. Sin embargo, se denota que persiste cierta cercanía con los vecinos hablantes de maya, debido a las posibilidades que podría reportar el pertenecer a un mismo origen "maya", en cuanto al establecimiento de redes de relaciones sociales, como las que se forman con el compadrazgo. Las relaciones familiares permanecen fuertemente arraigadas entre los pobladores, independientemente de que estén ubicados en lugares distantes de la ciudad, siendo una de las formas o mecanismos de reforzamiento de su lengua.

El hecho de que se prescinda de la regular transmisión de la lengua a los hijos, trae aparejados factores de índole social y educativa. Se sabe que la integración al ámbito urbano propicia, en gran medida, el alejamiento de la lengua indígena, por carecer de espacios de expresión oficializados, por lo que la lengua materna pierde utilidad en el espacio citadino. Francesc Ligorred afirma que cuando se hablan l'enguas diferentes, como el español y la maya, en un mismo espacio geográfico, los indígenas prefieren optar por una comunicación en español. No es de extrañar que esa "lealtad lingüística" muchas veces, en lugar de beneficiar, aísla e impide el enriquecimiento lingüístico en ambas lenguas. ${ }^{7}$

${ }^{7}$ Véase a Ligorred, Lenguas, 1992, p. 159. Por su parte, Andrés Medina resalta que las lenguas indígenas son una filiación comunitaria y regional. La importancia de la misma 
A pesar del rechazo de la lengua maya en los diferentes ámbitos oficiales de la ciudad, es significativo el hecho de que aproximadamente el $91 \%$ de los jefes de familia mayas encuestados piensen que se debe promover su lengua mediante su enseñanza en la escuela pública. Este dato es de gran relevancia, pues de concretarse tal idea, se podría influir de manera positiva en el diseño de las políticas educativas y comunicativas para la ciudad. Como sea, la receptividad oficial a esta necesidad de reconocimiento podría redundar en un factor de identidad étnica importante y, con ello, influir en otros elementos de la cultura.

Por otro lado, suele ser algo común que una lengua permanezca y se enriquezca a través de generaciones; pero vale la pena referirse a las implicaciones conceptuales que se desprenden del conflicto latente, intercultural, en que convive una lengua dominante y otra dominada, el cual, según Enrique Hammel, revela una "disglosia sustitutiva". Tal expresión alude, en esencia, a la relación asimétrica que se establece entre ambas. Dicho conflicto conlleva la incomunicación y la subordinación de la cultura propia, muchas veces con efectos traumáticos para el desarrollo psicosocial y cultural de los niños. ${ }^{8}$ Aunque Hammel lo

radica en su relación con la identidad. Medina, "Identidad", 1992, p. 14.

${ }^{\theta}$ Véase a Hammel, "Derechos", 1993, p. 75; Ronald Cohen, por otro lado, hace evidente que las relaciones entre la dicotomía nosotros/ ellos, establece papeles más específicos y crea presiones sociopsicológicas, y cada día sectores más extensos reclaman el reconocimiento de la etnicidad para una sociedad justa e igual, Co- planteó en su momento de mancra clara, es necesario recuperar un elemento que para nosotros es significativo. Nos referimos a la dominación del español sobre cualquier otra lengua indígena, como lo es la maya. Sobre esta relación de dominación, vale la pena referir que, en el trabajo de campo, surgieron numerosos casos en donde es evidente que los abuelos acostumbran a comunicarse con los nietos en lengua maya, aunque entienden el español; pero no logran que sus nietos a más de entender la maya, la hablen.

Si bien debieran plantearse alternativas realistas y factibles para contribuir al desarrollo y a la validación nacional de las lenguas indígenas, quizá podríamos empezar por reforzar el bilingüismo en aquellas instituciones que aglutinan y, por tanto, divulgan información, como son la escuela, las iglesias y los medios de comunicación; además de reconocer y alentar el papel activo de la familia en cl ámbito doméstico para la revitalización de la lengua maya.

\section{UNA NUEVA CARA CULTURAL CITADINA}

Por tradición, el trabajo de la milpa ha permitido un reforzamiento de la cul-

hen, "Ethnicity", 1978. Por su parte, el trabajo de Rodolfo Stavenhagen sobre la cuestión étnica, resalta que la teoría modernizadora atribuye valores diferentes a las manifestaciones culturales; tan es así que los grupos que no se apeguen al modelo ideal o establecido, serán considerados como refractarios o marginados, entre otros criterios. Stavenhagen, "Notas", 1984, p. 141. 
tura maya debido a la carga de símbolos y expresiones que lo acompañan y que son propias de esos quehaceres. Sin embargo, al reducirse la enseñanza y transmisión de este conocimiento a las nuevas generaciones, se las aleja del reforzamiento y la eficaz socialización dentro del grupo. La ciudad, por sus características modernizadoras e industriales, es por lo general aglutinadora de recursos y fuerza de trabajo, lo cual, naturalmente, no posibilita el desarrollo de este espacio étnico. De cualquier modo, los indígenas de Chetumal siguen, en un porcentaje representativo $(9.5 \%)$, trabajando la tierra. No obstante, el hecho es que cada día se ven más integrados a una economía no agrícola.?

Como establecimos al inicio de este trabajo, a la población indígena maya de Chetumal, de acuerdo con un primer análisis, la determinamos (aparte de por la lengua) por ciertas características perceptibles, derivadas del registro empírico, como son el vestido, el conocimiento y la transmisión de ritos, la música, la economía

\footnotetext{
${ }^{9}$ En un trabajo que se realizó sobre migrantes a la ciudad de México, Carmen Bueno afirma que la tierra es para los indígenas en la ciudad algo más que un instrumento económico de sobrevivencia, es el arraigo a algo propio, es el soporte de su identidad; Bueno, "Migración", 1994, p. 19. Por otro lado, Alicia Re, en su investigación sobre la identidad de los emigrantes en Yucatán, escribe que el símbolo milpa se encuentra en los argumentos y discursos de la identidad; es así que los migrantes han "mayanizado" su transformación en proletariado urbano por medio de la identificación de su espacio laboral con una milpa que, como ellos, se ha transformado en urbana. Re, "Sagrado", 1994, p. 44.
}

de traspatio, la literatura y la participación en organizaciones tales como los gremios. Bajo estas características se encuentra ubicado el $23.9 \%$ del total de los jefes de familia encuestados en la ciudad. Este porcentaje es significativo si partimos del hecho de que es el mismo registrado para los jefes de familia que hablan la lengua maya. Se puede establecer con certeza, además, que los hablantes de la maya son los que, al mismo tiempo, mantienen otros elementos culturales pertenecientes a su origen étnico. ${ }^{10}$ Este hecho no es casual: se debe, entre otras causas, a la permanencia de los mayas originarios de la ciudad y del propio estado de Quintana Roo, así como al papel desempeñado por las migraciones interpeninsulares que se han presentado constantemente desde el periodo que antecedió a la conversión del territorio en estado, en el año de 1974. ${ }^{11}$

${ }^{10}$ Lourdes Arizpe define al grupo étnico mazahua a partir de cómo se llaman a sí mismos y cómo se distinguen de los demás grupos. Como resultado valoró esencialmente a la lengua, la indumentaria, las creencias religiosas, los valores ideales y algunos aspectos de su cultura material. Véase Arizpe, Migración, 1978, pp. 199-213; George De Vos, por su parte, señala que un grupo étnico es algún grupo concebido a sí mismo como gente que comparte un pasado, De Vos, "Social", 1978.

${ }^{11}$ Quintana Roo, como otros estados de la república mexicana, experimentó políticas de poblamiento dirigidas a adquirir la categoría de estado. La ciudad de Chetumal, desde su fundación, ha vivido un constante movimiento poblacional que refiere migraciones no sólo interpeninsulares sino de otros estados del país. El desarrollo de un nuevo centro requería de fuerza de trabajo, porque se tenían espacios para absorber a quienes arribaran. La pobla- 
Los datos de la encuesta permiten identificar los lugares de procedencia de la población que habla maya en la capital del estado. Es notorio que el $46.8 \%$ ( 44 casos) de este grupo procede del mismo estado, o sea que son quintanarroenses. Esta población se encuentra distribuida entre un $20.2 \%$ de originarios o nativos de la propia ciudad de Chetumal, un $10.6 \%$ provenientes del municipio de Othón $P$. Blanco (que es el asiento de la capital del estado) y un $16 \%$ que han llegado de otros municipios de la entidad. En cambio, del total de mayas establecidos en la ciudad, son de otros estados de la península el $53.2 \%$ ( 50 casos). De ellos, $34 \%$ procede de Yucatán y $19.2 \%$ de Campeche; es decir, la lengua maya yucateca ha tenido en la ciudad un continuo apoyo de migrantes interpeninsulares. Esto se entiende, aparte de por la vecindad geográfica, por los vínculos histórico-culturales que ambas entidades han tenido con Quintana Roo. ${ }^{12}$ Estos datos nos conducen a dos conclusiones: $a$ ) la población maya (es decir, los primeros pobladores del estado) todavía mantiene una presencia que es notoria en la propia ciudad capital; y $b$ ) este fenómeno se amplía con las migracio-

ción indígena de la penisula ha tenido que adecuarse a los diferentes periodos económicos y políticos de la región; su distribución como fuerza de trabajo dependió en mucho de estas políticas gubernamentales. Al respecto, puede consultarse el trabajo de Bracamonte, Memoria, 1994.

${ }^{12}$ Tanto Campeche como Quintana Roo formaron parte del estado de Yucatán en la antigüedad. Campeche se separó de esta última entidad en 1858. Quintana Roo, por su parte, surgió como territorio federal en 1902. nes permanentes de grupos mayas yucatecos y campechanos a la ciudad de Chetumal.

Las transformaciones y cambios que ocurrieron en todo el estado, y en especial en el medio rural, a partir de la aplicación de programas de la reforma agraria y del desarrollo dirigido, afectaron al parecer de manera importante las formas de distribución territorial de la población indígena, tradicionalmente asentada en pequeñas comunidades dispersas. Con el tiempo, la población indígena que se fue estableciendo en Chetumal respondió a mecanismos por los que vio su permanencia ahí como una alternativa real de reproducción para su unidad doméstica. ${ }^{13}$

La migración de población maya a Chetumal tiene una larga tradición que empieza a principios de este siglo. Se puede suponer, entre otras cosas, que la búsqueda de mejores condiciones de vida y el hecho de encontrar en la ciudad condiciones que facilitan su reproducción como grupo étnico, han sido los principales condicionantes de este fenómeno. Por lo tanto, hay que dejar claro que, a pesar de los continuos movimientos migratorios a la ciudad (que no son solamente de mayas yucatecos, sino también de otros estados y regiones del

\footnotetext{
${ }^{13}$ Véase, acerca de un ejemplo similar, Iturralde, "Pueblos", 1991, p. 29. García y Oliveira definen la unidad doméstica como "el ámbito en donde los individuos organizan su reproducción cotidiana y generacional, donde tiene lugar la socialización de los nuevos miembros y el reforzamiento de los significados y motivaciones que fundamentan las actividades grupales". García y Oliveira, "Trabajo", 1994, p. 259.
} 


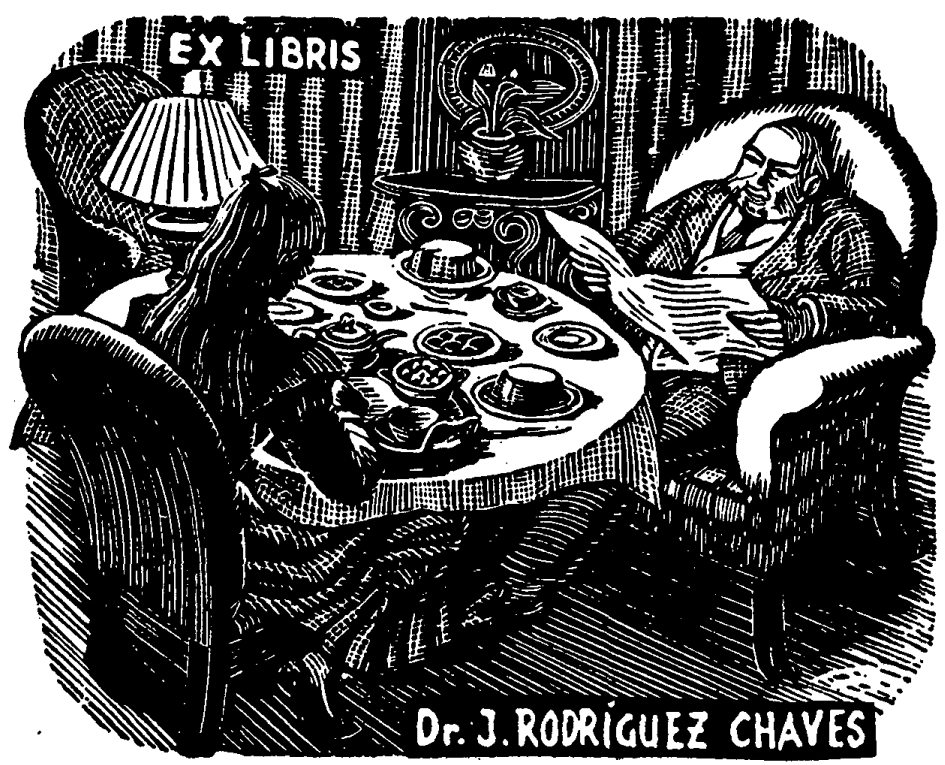

país), el contacto entre los diversos grupos no indica la desaparición del maya. Para Fredrik Barth, por ejemplo, la persistencia de los grupos étnicos en mantener el contacto implica no sólo criterios y señales de identificación, sino también una estructura de interacción que permite esta persistencia a pesar de las diferencias culturales lo cual actúa sobre ciertos aspectos, como en el aislamiento de los - rasgos culturales de ciertos sectores, evitando confrontaciones o modificaciones. $^{14}$

\footnotetext{
${ }^{14}$ Véase Barth, "Introducción", 1976, p. 18. Un texto que desarrolla ampliamente la persistencia de los pueblos indígenas en América Latina y la extensión "pacífica" del control administrativo-gubernamental y las políticas de "desarrollo", es el de Contreras, Cara, 1988.
}

El grupo maya de Chetumal ha mostrado cierta inmovilidad con respecto a su socialización; es decir, durante los primeros años de su crecimiento no sale de la ciudad, lo que significa que la mayoría de sus componentes tuvieron su primera socialización en su ciudad natal. ${ }^{15}$ El cuadro 1 nos muestra que, de esta población, el $29.8 \%$ permaneció o viajó a Chetumal a una edad muy temprana, antes de cumplir los once años, por lo que se infiere que es un grupo que fue socializado en la ciudad.

${ }^{15}$ Hemos definido por socialización, el periodo de formación hasta los primeros once años de exposición a un grupo social. Al respecto puede consultarse el trabajo de Pérez, Camus y Bastos, Todito, 1992. 
En cuanto a los migrantes mayas, el $54.2 \%$ llegaron antes de 1974 y en la siguiente década. Ello significa que fue en este periodo cuando los migrantes arribaron con mayor intensidad a la ciudad, lo cual puede relacionarse con la definición de ésta como -capital del estado y con el surgimien. to en ella de instituciones públicas y servicios.

Al ahondar en el análisis de los espacios donde sucede la socialización de la población maya radicada en la entidad, se ve que, la gran mayoría (70\%), fueron socializados fuera de la ciudad, o sea que son migrantes que llegaron a la misma después de cumplir los once. Lo anterior, y de acuerdo con los datos de procedencia, indica que tales migrantes trajeron consigo un cúmulo de información y símbolos étnicos de la región, por lo que éste resulta ser el mecanismo que refuerza continuamente a los variados patrones culturales mayas de la ciudad.

En un primer acercamiento, se ha mostrado la presencia y permanencia de la población étnica maya en la ciudad con los diferentes rasgos que caracterizan a ésta. El objetivo más importante de este trabajo, como establecimos al inicio del texto, es la relación de esa población con las distintas transformaciones socioeconómicas presentadas por ese hábitat. Se podría pensar que, en el periodo de migración más fuerte, la ciudad constituyó el lugar de destino más atractivo para la superación económica y la permanencia étnica, según lo muestra el cuadro 1: de la población maya que se encuentra en el ámbito urbano, 20.2\% son nacidos en la ciudad y un $79.8 \%$ nacieron fuera de la misma. Sin embargo, al insistir en el análisis de la permanencia de dicha población en la capital, se corre el riesgo de olvidar -además de su contribución a la estructura social y económica de la ciudad-, los cambios en su propio estatus socioeconómico y su integración sociocultural.

\section{DESARROLLO CUTURAL Y MODERNIDAD}

Mucho se ha hablado de lo que es la cultura indígena y de la añoranza que se tiene de aquella civilización maya que, según las exigencias urbanas y el prototipo de las ciudades contemporáneas, parece estar agotada. Sin embargo, en otro plano, como por ejemplo en la actividad turística, vemos cómo la comercialización de esa cultura, que se ha denominado tradicional, puede contribuir a atraer el interés de los habitantes de otras naciones. Uno de los rasgos que adquiere funcionalidad para la sociedad urbana e industrial, y que procede de la matriz cultural maya, se origina en aquello que la literatura sobre los grupos indígenas denomina muchas veces elementos materiales (como la vestimenta, el tipo de construcción de vivienda) y otros no materiales (como las costumbres religiosas).

En cuanto a una de las características materiales, el vestido, los resultados de la encuesta muestran que $61 \%$ del total de la población maya radicada en Chetumal conserva su vestimenta tradicional. Es interesante observar que, dentro de la propia capi- 
Cuadro 1. Distribución de la población migrante maya, según su periodo de exposición en Chetumal

\section{Periodo de exposición} en Cbetumal

Nativos por adopción

Después de mayo 1991

Entre mayo 1988 y mayo 1991

Entre mayo 1983 y abril 1988

Entre 1974 y 1983

Antes de 1974

Fecha desconocida

Socializados en Chetumal

Socializados fuera

FUENTE: ESOYGECH, CIQRO, 1993.

\section{Frecuencia absoluta}

$\begin{array}{rr}9 & 9.6 \\ 5 & 5.3 \\ 6 & 6.4 \\ 10 & 10.6 \\ 21 & 22.3 \\ 20 & 21.3 \\ 4 & 4.3 \\ 28 & 29.8 \\ 66 & 70.2\end{array}$

Frecuencia relativa (porcentaje)

9.6

6.4

0.6

2.3

4.3

70.2 tal, sigue vigente este patrón, reafirmando nuestra hipótesis, arriba formulada, sobre su permanencia allí como población étnica maya. Tal vestimenta es usada, generalmente, por los padres de los jefes de familia (47\%), seguidos por las cónyuges de los mismos (37\%), y por el propio jefe de familia (16\%). Otra constatación relevante, que nos facilitan los datos de la encuesta, se relaciona con la frecuencia con que se utiliza ésta. El 59\% de los que la usan lo hacen todos los días, seguidos por los que lo hacen en las fiestas religiosas con un $18.4 \%$ y en las fiestas familiares con un $14.3 \%$. Hay además un $8 \%$ que la usa en otras ocasiones.

Por otro lado, existen actividades de interés, como las reuniones religiosas, sociales y económicas realizadas en el solar o huerto doméstico, las cuales son sin duda parte de su acervo cultural. En cuanto a las reli- giosas, por orden de importancia, tenemos las novenas que, aunque de origen colonial, denotan el sincretismo entre lo católico y las reminiscencias de lo nativo, con un 29.9\%; los gremios, organizadores de fiestas religiosas y comunitarias estructurados según el modo de las cofradías, con $17.1 \%$ y las peregrinaciones o procesiones con un $15.7 \%$. Para las actividades de carácter social, el solar es usado de manera predominante en las fiestas familiares y de los gremios en un 40 por ciento.

En lo que a las actividades económicas se refiere, el $55 \%$ de los mayas practica actividades de horticultura, fruticultura, avicultura y ganadería menor. El resto (45\%) no tiene la oportunidad de realizar alguna labor relacionada con el campo. Sin embargo, dentro de esta proporción que lleva a cabo alguna actividad económica en su solar o huerto doméstico, la horti- 
cultura tiene el mayor peso con $36.5 \%$, seguida por la fruticultura, practicada en un $31 \%$ de los casos. La avicultura, como actividad de este tipo, la practica un $23 \%$ de los jefes de familia mayas. Por lo demás, los productos que se obtienen del huerto cada vez son menos y se destinan, por lo general, al autoconsumo; en tal actividad participa, en la mayoría de los casos, toda la familia. Es así que este trabajo se lleva a cabo como parte de la rutina diaria y queda bajo el control, casi siempre, de las mujeres y los hijos. Esta actividad contribuye a la dieta familiar aportando un conjunto diversificado de frutas, legumbres y carnes $y$, por tanto, aumenta el ingreso de la unidad doméstica.

Acerca de los campesinos mayas de Yucatán, Arturo Warman ha realizado una interesante descripción integral de sus actividades económicas en sus huertos, en la que destaca cómo éstos se ubican alrededor de las casas y son un espacio de intensa actividad. En el mismo se crían gallinas y cerdos, que se alimentan de maíz y de las sobras de la alimentación humana. Con excepción de algunos animales de cría que se destinan al mercado, la variada producción se dirige al autoconsumo. Hoy en día, como observó Warman, crece más la parte de la producción hortícola que se vende al por menor en el pueblo o ciudad más cercana o a acopiadores en pequeña escala que recorren los pueblos para venderla en las ciudades. Otro cambio importante que se da en el seno de las familias, pero que se considera relativamente reciente en el trabajo del huerto, es el uso de la mano de obra femenina, infantil y de los ancianos. ${ }^{16}$ Lo anterior puede equipararse, en menor medida, con la actividad realizada en los solares domésticos en Chetumal, así como la participación de toda la familia en las actividades económicas que aseguran su reproducción.

El sesgo que esta labor adquiere en las ciudades se debe, principalmente, a dos aspectos: $a$ ) la falta de espacio para plantar un huerto, ya que los terrenos son caros y el área reducida; $b$ ) la inserción en el mercado de trabajo asalariado. Al respecto, se ha mencionado que el trabajo asalariado cada vez cobra mayor importancia para la reproducción de la unidad familiar, pues la organización de ésta tiende a subordinarse a la venta de fuerza de trabajo en el exterior. Así, el trabajo asalariado se vuelve, en muchos casos, la actividad principal de la familia, mientras que las actividades no asalariadas pasan a ser complementarias. ${ }^{17}$

Las mujeres mayas participan de manera importante en el manejo de los recursos. Al respecto, Magalí Daltabuit señala que ellas siempre han empleado, como recurso económico, las labores domésticas y del huerto. ${ }^{18}$

Al estudiar el manejo de éste en la ciudad, nos percatamos que puede ser utilizado también como paráme-

\footnotetext{
${ }^{16}$ Véase sobre el particular a Warman, "Estrategias", 1985 , p. 40. Otro libro que aborda los aspectos de la milpa y la producción agrícola entre los mayas de Yucatán es el de Terán y Rasmussen, Milpa, 1994.

${ }^{17}$ En relación con este punto, puede verse el trabajo De Teresa, "Encuesta", 1991, pp. 184-185.

${ }^{18}$ Véase para mayor información a Daltabuit, Mujeres, 1992, p. 59.
} 
tro para medir la continuidad de los patrones económicos y culturales que manejan estas familias; es decir, se observan con cierta claridad estrategias para acopiar productos complementarios o para el manejo del espacio, como parte de las relaciones sociales y familiares.

En un plano distinto, sobre la pertenencia a un gremio, $28 \%$ de los mayas declara proceder de alguno cuyo lugar de origen es Chetumal en un $66.6 \%$, Peto en un $16.7 \%$ y Mérida en un $16.7 \%$, lo cual da un total de $33.4 \%$ de procedencia yucateca. Lo interesante de estos datos es que nos permiten saber que, dentro de la propia capital del estado, se siguen tradiciones festivas y organizativas de origen maya. Asimismo, una de las actividades que ha caracterizado a los mayas la constituye la transmisión de conocimientos y experiencias o tradiciones domésticas a los hijos. En este contexto, para el caso de Chetumal la transmisión de las tradiciones culinarias ocupa un lugar predominante con un $24 \%$; y la siguen el conocimiento de la cuentística maya (18\%), de la lengua maya (15\%), de las leyendas $(12.4 \%)$, de las técnicas de producción agrícola (2\%), del vestido (2\%), de las artesanías (1\%), y otros con un 25.6 por ciento.

Existen además, en la actualidad, ciertas ceremonias llenas de símbolos que hablan de su identidad y que constituyen una expresión notable de la cultura maya: el bets'mek y el cha'a chaak, entre otras. ${ }^{19}$ Según la infor-

${ }^{19}$ Cha'achaak: ceremonia de propiciación de la lluvia (Terán y Rasmussen, Milpa, 1994, p. 62). Hets'mek: a horcajadas, llevar a un ni- mación captada por la encuesta, todos los jefes de familia que componen el grupo maya radicado en Chetumal tienen conocimiento de la ceremonia del bets'mek. El 51.4\% manifiesta que la ha practicado y $23.2 \%$ de ellos declara que la practica actualmente. En relación con el cba'acbaak, existe una tendencia similar, puesto que es apreciable el conocimiento del mismo en un $29.8 \%$ de los jefes de familia. Las tradiciones musicales y de danzas que caracterizan hoy al grupo maya señalan que todos los jefes de familia radicados en la ciudad saben de danzas, como la jarana, la cabeza de cochino y la chiclera. En cuanto a los bailes de la región caribeña, como punta, rock, reggae, calipso y cumbia, la mayoría (83\%) afirma conocerlos.

Las características mayas expuestas que permanecen en la ciudad son dinámicas: han sido y siguen siendo modificadas por el contacto con otros patrones culturales. Sin embargo, los grupos indígenas asumen, naturalmente, sus rasgos, no desde el punto de vista ajeno, sino desde el propio. Se ha dado en llamar tradicional a lo indígena y a los productos que esta población elabora. Pero el consumo de las "artesanías" por los diferentes grupos sociales se caracteriza por el espacio donde ocurre; es así que no es lo mismo vestir de manera cotidiana el hipil, que usarlo ocasionalmente en determinados "bailes tradicionales"; y no es igual el consumo que la utilidad de lo tradicional, de-

no cabalgando en las caderas, ritual de adscripción al papel sexual que corresponde a los menores (Barrera, Diccionario, 1980 p. 205). 
pende directamente de quién y cómo lo use. ${ }^{20}$

\section{OPCIONES LABORALES DE LA POBLACIÓN MAYA}

En este apartado se dan los resultados obtenidos en cuanto a la interrelación entre la presencia de la población indígena en Chetumal y su mercado de trabajo, factores ambos decisivos en el análisis del entorno social y cultural que nos ocupa.

Habiendo precisado los rasgos esenciales de la población indígena maya, nos corresponde analizar el conjunto de oportunidades laborales que ofrece la ciudad de Chetumal para la eventual incorporación de fuerza de trabajo. Este mercado suele considerarse allá el más importante escenario de interacción entre las unidades de reproducción de mano de obra y la sociedad en su conjunto, a la cual configuran características fundamentales en cuanto a estructura y organización. ${ }^{21}$

\footnotetext{
${ }^{20}$ Néstor García Canclini definió el consumo cultural como "el conjunto de procesos socioculturales en que se realiza la apropiación y los usos de los productos"; García, Consumo, 1993 , p. 24 . Es necesario referir que este fenómeno ha sido generado y reproducido históricamente de acuerdo con los planes que los gobiernos imponen en los países latinoamericanos; aunque hay que señalar que los grupos étnicos mostraron y continúan mostrando una capacidad de resistencia, favorecida por las contradicciones internas del proyecto homogeneizador. Al respecto, puede consultarse el trabajo de Díaz, Autonomía, 1991.

${ }^{21}$ Véase un abundamiento al respecto, en González, "Público", 1986, p. 192.
}

Los datos estadísticos que aquí se evalúan como base para la discusión, comprenden rubros que van descle el nivel de educación, salarios y tipo de ocupación, hasta ramas de actividad y peculiaridades del sector productivo. Además, se incorporan datos acerca del tiempo de residencia, como parte de la formación de la mano de obra. Un factor que consideramos de suma importancia al interrelacionar esta información, es la distribución de la mano de obra en Chetumal, según su ingreso y su periodo de exposición a la ciudad o ámbito social específico.

En lo fundamental, la región sur del estado de Quintana Roo parece caracterizarse por dos actividades económicas principales: el comercio de importación y los servicios a realizarse en Chetumal, por un lado, y la agroindustria de la caña de azúcar en la región del río Hondo, por otro. No es casual, por tanto, que la fuerza de trabajo haya tenido que dirigirse hacia estas ofertas. Sin embargo, no debe olvidarse que el surgimiento y la consolidación de la ciudad de Chetumal como centro administrativo han estado históricamente relacionados con las actividades públicas y de servicios. Su dinámica de desarrollo, como región de actividades economicas, está centrada en el sector terciario. Aspectos como la migración y la colonización inducida por la federación, durante la década de 1970, propiciaron nuevos modelos de organización territorial y de crecimiento económico. Además, el escaso fomento industrial $y$ el desarrollo infraestructural de la zona norte por el turismo -en especial desde el impulso dado al corre- 
dor Cancún-Tulum en 1974-, ${ }^{22}$ ha determinado como opción preferencial para el sur la apertura de espacios laborales en el sector terciario o de servicios.

Al abordar el proceso de desarrollo de la ciudad de Chetumal y sus actuales condiciones de empleo, es necesario considerar que el continuo movimiento de la estructura ocupacional suele concebirse como un resultado de la operación del mercado de trabajo en un contexto de salarios bajos y políticas de incremento del empleo. Sin embargo, el ciclo de desarrollo doméstico -entendido como un im. portante generador de cambios en la organización y la estructura de la unidad doméstica- reacciona ante tales condiciones del mercado de trabajo, como en un permanente proceso de acomodo; en él, los miembros de las unidades cambian de empleo según las ofertas del mercado de trabajo y según sus condiciones domésticas. ${ }^{23}$ Para el caso de Chetumal, las unidades domésticas se acomodan básicamente como fuerza laboral en el sector terciario (84.7\%). Lo anterior revela, por un lado, que la mayoría de los empleos exigen una especialización y una mayor capacitación o educación formal y, por otro, que el rubro de los servicios públicos es el de mayor atracción, aun con los salarios más bajos.

\footnotetext{
${ }^{22}$ Acerca de los procesos de colonización inducida y el fomento de la zona norte, puede consultarse, respectivamente, a Mendoza, "Impacto", 1997; Martí, Cancún, 1985, y Arnaiz, "Turismo", 1992.

${ }^{23}$ Véase González, "Público", 1986, p. 214.
}

Es sabido que, en la mayoría de las ciudades del país, la población que migra -en especial la que proviene del ámbito rural- enfrenta dificultades para encontrar empleo. Agustín Escobar Latapí, al realizar su estudio de la ciudad de Guadalajara, atribuye estas dificultades a que los migrantes carecen, por lo general, de capacitación en los oficios y de una socialización que les permita independizarse u obtener buenos trabajos en pequeños talleres manufactureros. ${ }^{24}$

En Quintana Roo, según datos censales del INEGI (1990), el 64.9\% de la población económicamente activa trabaja en el sector servicios y ello, en lo general, muestra la tendencia económica del estado. De la encuesta EsoyGECH se obtuvo que la distribución de la población maya en los sectores productivos de Chetumal es la siguiente: el sector terciario absorbe $76.8 \%$ del total de la fuerza de trabajo indígena, seguido con $12.3 \%$ por el secundario $y$ con $10.9 \%$ por el primario. Es innegable que estos datos confirman la decisiva influencia que ha tenido y tiene en Chetumal el sector servicios. En el cuadro 2 , se presentan los resultados de los sectores productivos de la ciudad, en relación con la población empleada.

Vale la pena precisar que algo similar ocurre en las trayectorias laborales de los grupos étnicos de Guatemala, que presentan una tendencia creciente hacia la diversificación. Al iniciar su inserción en el trabajo, parten de las actividades agrícolas, pero comienzan a derivar hacia el comercio y los servi-

\footnotetext{
${ }^{24}$ Véase Escobar, Sudor, 1986, p. 161.
} 
cios cuando migran a la ciudad; ello encuentra su máxima expresión en la actualidad con las muchas actividades que ofrece la ciudad capital. ${ }^{25}$

Por otro lado, observamos que, para el caso de la ciudad de Chetumal, esta diversificación registra una incidencia de tipos de empleo relativamente específicos y localizados: $67.6 \%$ laboran como empleados, los trabajadores por cuenta propia representan un $21.6 \%$ del total y los empresarios un 5.4\%; sin embargo, entre peones y jornaleros tenemos un $4.1 \%$, y otros, no especificados, suman el 1.4\%. Como se observa, la ocupación de más alto índice es la de empleado. Al relacionar esta diversificación con los salarios, llama la atención la tendencia siguiente: $37.8 \%$ tiene percepciones bajas, le sigue un $14.9 \%$ con salarios muy bajos, pero lo más significativo es que $25.7 \%$ de los jefes de familia mayas, percibe salarios insuficientes. ${ }^{26}$ El cuadro 3 nos muestra el tipo de empleo u ocupación de la población en general.

Para comprender los datos anteriores, podemos considerar que existen dos tipos de mercados laborales: el formal, caracterizado por puestos

${ }^{25}$ Un estudio recomendable que recoge información al respecto es el de Pérez, Camus y Bastos, "Trayectorias", 1993, p. 533.

${ }^{26}$ Para una precisa distinción y un mejor manejo, se procedió a estratificar a la población, según el ingreso, con los siguientes rangos: de subsistencia, inferior al salario mínimo legal; muy bajos, de uno a dos salarios mínimos; bajos, más de dos a tres salarios mínimos; insuficientes, más de tres a cinco salarios mínimos; medios, más de cinco a diez salarios mínimos; medios altos y altos más de diez salarios mínimos. de trabajo en empresas organizadas o en servicios individuales demandados por gente de más altos ingresos; y el informal, comprendido por las personas que trabajan por cuenta propia, o en empresas chicas, o en servicios individuales de baja productividad, como sería el doméstico remunerado. En el sector informal, según Tokman, se concentra gran parte de la pobreza de las ciudades latinoamericanas. ${ }^{27}$

De acuerdo con esta clasificación de los mercados laborales, notamos que, en la ciudad de Chetumal, la presencia de trabajadores por cuenta propia o no asalariados supone que la informalidad es muy alta en la población maya. Y si enlazamos este tipo de empleo con la escolaridad de la población indígena, destaca la escasa capacidad de esta población para insertarse en el mercado capitalino. Al respecto, parece ya un lugar común

${ }^{27}$ Victor Tukman, citado en Brígida García, menciona que existe una falta de capacidid en los sectores modernos para incorporar a la mano de obra. En el mismo trabajo, la autora reflexiona sobre las diversas precisiones conceptuales del término sector informal. García, Desarrollo, 1988, p. 44. Como se sabe, existen numerosos estudios relacionados con la utilización de los conceptos del trabajo "formal" e "informal". Aunque no es nuestro propósito exponer las principales interpretaciones al respecto, para mayor abundamiento puede verse el trabajo de Agustín Escobar, quien senala que la homogeneidad/diferenciación de la clase obrera debe analizarse a partir de la organización del trabajo $y$ no de dicotomías tales como formal-informal. Escobar, Sudor, 1986, p. 300. Sin embargo, no deja de ser manejada como parte del análisis del mercado laboral en Guadalajara, al referir que la "distinción formal-informal puede operacionalizarse con cierta facilidad al clasificar las unidades productivas de acuerdo con su tamaño, su posesión de 
Cuadro 2. Distribución de la población según su sector productivo (en porcentaje)

$\begin{array}{lccc}\text { Sectores productivos } & \text { Maya } & \text { No maya } & \text { Población total } \\ \text { Primario } & 10.9 & .4 & 2.7 \\ \text { Secundario } & 12.3 & 12.8 & 12.6 \\ \text { Terciario } & 76.8 & 86.8 & 84.7 \\ \text { Total } & 100 & 100 & 100\end{array}$

FUENTE: ESOYGECH, CIQRO, 1993.

Cuadro 3. Distribución de la población, según su tipo de ocupación (en porcentaje)

$\begin{array}{lccc}\text { Tipo de ocupación } & \text { Maya } & \text { No maya } & \text { Población total } \\ \text { Empleados } & 67.6 & 75.2 & 73.5 \\ \text { Peones y jornaleros } & 4.1 & .8 & 1.5 \\ \text { Cuenta propia } & 21.6 & 12.4 & 14.4 \\ \text { Empresarios } & 5.4 & 10.9 & 9.7 \\ \text { Trabajadores familiares }^{\mathrm{a}} & - & - & - \\ \text { No especificado } & 1.3 & 0.7 & .9 \\ \text { Total } & 100 & 100 & 100\end{array}$

\footnotetext{
a En este rubro no se obtuvo información, sin embargo, es necesario mencionarlo como un indicador más del empleo.

FUENTE: ESOYGECH, CIQRO, 1993.
}

sostener que, en los sectores modernos de la economía urbana, existe un fracaso para absorber fuerza de trabajo a una tasa adecuada al crecimiento de la población y a las características de los trabajadores. ${ }^{28}$

registro en la cámara industrial que les toque, el que el dueño haga o no trabajo manual, y la contratación formal de mano de obra"; Escobar, "Patrones", 1986, p. 173.

${ }^{28}$ Una discusión que aborda los enfoques técnicos de la urbanización rápida y de las
Aunque no se distinguen los datos relacionados con el sexo de los trabajadores mayas en Chetumal, es probable que, dentro del grupo de asalariados o empleados y por cuenta propia, se concentren también una gran cantidad de mujeres, pues son actividades que requieren de menos capacitación y, por lo común, de un tiempo laboral migraciones en el contexto de los "obstáculos" al desarrollo, se presenta en Ramírez y Yocelevzky, Política, 1986, pp. 23-27. 


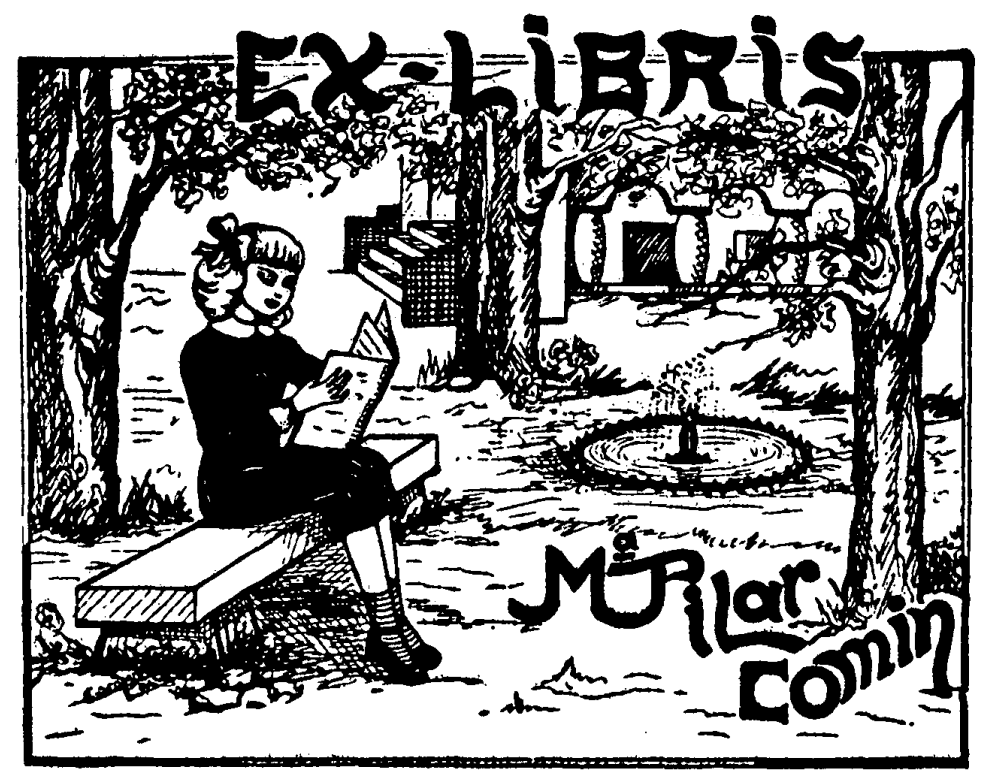

que se adecua con las necesidades domésticas de la mujer. La elección de actividades no asalariadas, más que una opción cómoda, revela una estrategia que la unidad doméstica emplea para su subsistencia. Podría establecerse que la variable étnica incide en la definición del tipo de trabajo y que, por ello, el conjunto de actividades económicas distintas es una característica de las estrategias de reproducción de las unidades domésticas mayas en Chetumal.

Por otra parte, no es un secreto que en México la tendencia al estancamiento del poder adquisitivo es un hecho, y que gran parte de los trabajadores asalariados deben complementar sus ingresos con trabajos múltiples, tiempo extra, actividades no asa- lariadas y subsidios públicos. Lo anterior parecería descartar a la cuestión étnica como condicionante, pero los datos muestran que la población más desfavorecida en Chetumal, por su tipo de empleo y sus ingresos, es la maya. Es cierto que dentro de este grupo existen diferencias, pero en general, y comparándolo con la población no indígena, ésta queda en una situación de mayor rezago.

La población maya establecida en la ciudad tiene diferentes periodos de exposición al ámbito social y cconómico, por lo que la relación entre ingreso y tiempo de residencia es de suma importancia para ampliar el análisis de su condición en el mercado laboral; en el cuadro 4 se hace referencia a estas correlaciones. 
Hemos considerado nativos por adopción a los migrantes que arribaron a Chetumal antes de los once años de edad y que han permanecido en el núcleo urbano; este grupo, que representa a más de la mitad, percibe salarios ubicados en la categoría de bajos. Otros parámetros nos muestran que entre nacer en la ciudad y nacer fuera, los porcentajes no varían, es decir, las oportunidades de obtener un salario no dependen del lugar de origen del ciudadano. Por su parte, la población no maya se ubica con un $35 \%$ en salarios insuficientes y son los nacidos y socializados en la ciudad; sin embargo, existe una población con el mismo porcentaje que percibe salarios bajos y que su tipo de ocupación es el mismo, los empleados. Al respecto, y de manera similar al caso de Chetumal, conviene referir cómo, en un estudio realizado en la ciudad de Guatemala, se encontró que los grupos étnicos mayas, por su baja escolaridad, buscan insertarse en la estructura productiva de manera más informal, concentrándose en el comercio. Asimismo, sus relaciones laborales son más precarias, sobre todo en términos de regulación del trabajo e ingresos, los cuales podemos ubicar como insuficientes. ${ }^{29}$

En relación con las ramas de actividad en que se ubican los trabajadores mayas en la ciudad de Chetumal, en el cuadro 5 se muestra que la administración pública absorbe un $29.3 \%$, el comercio al menudeo un $16.2 \%$ y

${ }^{29}$ Pérez, Camus y Bastos, "Trayectorias", 1993, p. 522. los siguen con porcentajes similares que rebasan el $9 \%$, la agricultura, la construcción y los bancos. Por su parte, los servicios domésticos absorben más del $6 \%$ de la fuerza laboral. La información sobre su inserción en otras ramas de la actividad productiva, que requieren una mayor especialización de la fuerza laboral, no parece significativa, ya que en ningún caso rebasa 10 por ciento.

Si analizamos lo anterior con respecto al tiempo de residencia en Chetumal de la fuerza laboral maya, observamos que en la administración pública labora un $31 \%$ de los que nacieron y fueron socializados en la ciudad; además, con un índice del $29.2 \%$ se encuentran los nacidos y socializados fuera de la misma, y con un $28.5 \%$ los que se definen como nativos por adopción. En relación con la agricultura, que para nosotros es de gran importancia dada su procedencia ocupacional étnica, tenemos que el mayor porcentaje lo obtuvieron los nativos por adopción con $14.3 \%$ y, cercano a este rubro, con $12.5 \%$, se encuentran los nacidos y socializados en Chetumal.

En la ciudad capital se aprecia que, para la población no maya, un rubro ajeno es la rama agrícola. De manera similar, ésta población presenta que un $41 \%$ de su fuerza laboral en la administración pública, y que $50 \%$ de ella, son migrantes por adopción, y un $46.7 \%$, nacidos y socializados en Chetumal. La gran diferencia para esta población radica en la agricultura, dado que en ella no se encontró fuerza de trabajo no maya. Las posibilidades de integrarse a los servicios 
Cuadro 4. Distribución de la población maya, según su tiempo de resistencia y salario (en porcentaje)

Tiempo de resistencia/salario

Nacido y socializado fuera

Nacido y socializado en Chetumal

Nativo por adopción

Nacido en Chetumal

Nacido fuera

Socializado en Chetumal

Socializado fuera

$\begin{array}{llllll}A & B & C & D & E & F\end{array}$

$\begin{array}{llllcl}5.9 & 15.7 & 35.3 & 25.5 & 13.7 & 3.9 \\ 0 & 12.5 & 37.5 & 25 & 18.7 & 6.3 \\ 0 & 14.3 & 57.1 & 28.6 & 0 & 0 \\ 0 & 12.5 & 37.5 & 25 & 18.7 & 6.3 \\ 5.2 & 15.5 & 37.9 & 25.9 & 12.1 & 3.4 \\ 0 & 13 & 43.5 & 26.1 & 13 & 4.4 \\ 5.9 & 15.7 & 35.3 & 25.5 & 13.7 & 3.9\end{array}$

$\mathrm{A}=$ Subsistencia, $\mathrm{B}=$ Muy bajos, $\mathrm{C}=\mathrm{B}$ ajos, $\mathrm{D}=$ Insuficientes, $\mathrm{E}=$ Medios, $\mathrm{F}=$ Medio alto $\mathrm{y}$ alto; en la nota 28 se refieren los rangos de los ingresos salariales.

FUENTE: ESOYGECH, CIQRO, 1993.

Cuadro 5. Distribución de la población, según la rama de actividad (en porcentaje)

Rama de actividad Maya Nomaya Población total

$\begin{array}{lrrr}\text { Agricultura } & 9.5 & 0 & 2.1 \\ \text { Ganadería } & 1.4 & .4 & .6 \\ \text { Manufactura } & 1.4 & 3 & 2.6 \\ \text { Electricidad/Gas } & 1.4 & 1.9 & 1.8 \\ \text { Construcción } & 9.5 & 7.9 & 8.2 \\ \text { Comercio menudeo } & 16.2 & 9 & 10.6 \\ \text { Comercio mayoreo } & 5.4 & 4.9 & 5 \\ \text { Restaurantes/Hoteles } & 1.4 & 3 & 2.6 \\ \text { Transporte } & 1.4 & 5.3 & 4.4 \\ \text { Bancos } & 9.5 & 14.6 & 13.5 \\ \text { Servicios personales } & 6.8 & 6.4 & 6.5 \\ \text { Servicio doméstico } & 6.8 & 2.6 & 3.5 \\ \text { Administración pública } & 29.3 & 41 & 38.6 \\ \text { Total } & 100 & 100 & 100\end{array}$

FUENTE: ESOYGECH, CIQRO, 1993. 
son mayores para ella, pues su relación con el ámbito urbano es mayor.

\section{EDUCACIÓN Y EMPLEO}

La variable educativa se impone pues, como uno de los indicadores importantes que definen el acceso a trabajos mejor remunerados. Pero hay que considerar al respecto el costo social y económico de la misma. El que un miembro de una unidad de bajos ingresos acuda a la escuela significa para aquélla prescindir en muchas ocasiones de brazos para el trabajo y de su apoyo a la economía de la familia. Actualmente, la capacitación y la instrucción están adquiriendo un papel muy importante en el proceso de superación y en el avance socioeco. nómico de un individuo. La percepción sobre su importancia es variable. En ocasiones se minimiza su influencia no sólo en el aumento de la productividad, sino también en el desarrollo económico; o bien se la ha valuado en exceso en los procesos de cambio social y de progreso económico. En nuestro estudio, consideramos a la educación como un indicador de la condición socioeconómica de la familia, un factor de gran importancia para el mejoramiento de sus condiciones de vida y de bienestar material. Asimismo, evidenciamos el alto poder discriminatorio de esta variable como condicionante del grado de acceso a los servicios y, especialmente, de la calidad de los ingresos. ${ }^{30}$

\footnotetext{
${ }^{30}$ Para Luisa Gabayet Ortega, "la educación representa para las familias la mejor manera de
}

Lo anterior se aprecia en los estudios realizados en la ciudad de Guadalajara, en donde la composición social de la unidad doméstica cambia a lo largo de su ciclo de reproducción. Por tanto, la familia no es un clemento fijo, sino flexible y relativo. Iil bienestar económico o la pobreza de la unidad familiar también varía a lo largo del ciclo doméstico. Es decir, que la pobreza o el bienestar de una unidad doméstica dependen no solamente del lugar que sus miembros ocupan en el mercado de trabajo, sino, en mucho, del grado de desarrollo reproductivo en que la unidad se encuentra. La educación formal, o el propio nivel de escolaridad, cstán sujetos a variaciones que tienen que ver tanto con la unidad doméstica como con su tiempo, es decir, con este ciclo de desarrollo reproductivo de la unidad familiar. La decisión de dar educación formal a los hijos, de mandarlos a la escuela, es tomada en el interior de esta unidad y depende de la situación social y económica por la que esté pasando mientras los niños están en edad escolar. ${ }^{31}$

En relación con los grupos indígenas, la perspectiva dominante en la apreciación de la integración social ha insistido en que su nivel de educación es más bajo en relación con el promedio general. En este contexto,

lograr movilidad social y también una de las inversiones más favorecidas. Así, la estrategia de mandar a los hijos al mercado de trabajo o darles mayor educación son selectivas y provienen de una racionalización"; Gabayet, "Diferenciación", 1986, pp. 264-265.

${ }^{31}$ Véase la investigación de González, "Público", 1986, p. 222. 
Cuadro 6. Distribución de la población, según su nivel educativo (en porcentaje)

\section{Educación}

Analfabetas

Sólo alfabetizados

Primaria incompleta

Primaria completa

Secundaria incompleta

Secundaria completa

Preparatoria incompleta

Preparatoria completa

Universidad incompleta/ completa

Estudios técnicos con primaria o secundaria acabada

Normal básica

Total

\section{Total de la población}

$\begin{array}{rrr}9.4 & 14.9 & 7.7 \\ 28.2 & 31.9 & 27.1 \\ 21.4 & 23.4 & 20.7 \\ 8.9 & 9.6 & 8.7 \\ 8.1 & 6.4 & 8.7 \\ 8.7 & 6.4 & 9.4 \\ 4.8 & 2.1 & 5.7 \\ 2.0 & 1.1 & 2.3 \\ 4.6 & 2.1 & 5.4 \\ & & \\ 3.1 & 2.1 & 3.3 \\ 0.8 & 0 & 1.0 \\ 100 & 100 & 100\end{array}$

FUENTE: ESOYGECH, CIQRO, 1993.

ie considera que la falta de educación ormal es la causa principal de su bao nivel de vida. La encuesta socioecolómica ESOYGECH captó información - elevante relacionada con esta variaJle; en el cuadro 6 se muestra el caso te los jefes de familia radicados en Thetumal.

Es evidente que los jefes de familia adicados en la ciudad tienen un nirel educativo muy bajo. Más de $9 \%$ no ienen ninguna educación, o sea, no Jueden leer ni escribir ni un recado. Isimismo, más de $28 \%$ saben leer y zscribir alguno y nada más. El $21 \%$ tieien sólo el nivel de primaria incomsleta. Esto significa que la mitad 49.6\%) del total de los jefes de famiia tienen un nivel educacional que va sntre el alfabetismo formal y la prima- ria incompleta. Por su parte, los que han completado la primaria representan sólo $9 \%$ aproximadamente. Sin embargo, $17 \%$ tiene secundaria completa o incompleta. Los que han cursado la preparatoria, completa o no, constituyen solamente $7 \%$. Se puede apreciar, asimismo, que los que han alcanzado el nivel universitario representan una mínima proporción: apcnas un $4.6 \%$. El resto (3.9\%) se distribuye entre los estudios técnicos y comerciales con primaria y secundaria acabada (3.1\%) y la normal básica $(0.8 \%)$. El nivel de posgrado, completo o incompleto, no está representado.

$Y$ si la educación en promedio es baja en el total de los jefes de familia, para la población maya la situación es 
aún peor: $15 \%$ del total de este grupo es analfabeta, $32 \%$ del mismo posee el nivel de alfabetizado, y $23 \%$ empezaron los estudios de primaria, pero por algún motivo no pudieron terminarlos. Es decir, y como se había establecido, más del $55 \%$ está entre el nivel de alfabetizados y el de primaria incompleta. Además, los jefes de familia mayas con nivel primario completo constituyen el $10 \%$, y el nivel de secundaria fue iniciado y completado sólo por un $13 \%$ aproximadamente. En lo que al nivel universitario se refiere, éste fue alcanzado apenas por un $2 \%$ de los mayas. (Del resto de la población, $2.1 \%$, posee estudios técnicos y comerciales con secundaria concluida.) Ninguno de ellos, sobra decirlo, ha estudiado la normal básica ni tampoco ha empezado o terminado algún posgrado. Lo anterior nos permite confirmar que el nivel de educación de la población maya en Chetumal se encuentra por debajo del promedio de la población no maya. Para el caso de los no mayas, el analfabetismo alcanza 7.7 por ciento.

En un análisis comparativo entre los jefes de familia de características mayas y no mayas, el analfabetismo es aproximadamente el doble (94\% más alto) entre los mayas. O sea, el analfabetismo de los grupos no mayas representaría apenas el $52 \%$ del exhibido por los jefes de familia mayas. La cantidad de alfabetizados que no han terminado la primaria, considerados en un nivel de educación bajo, es mayor en la población maya en un $16 \%$. Y en el nivel de primaria completa, todavía la proporción es más alta en la población indígena en un $10 \%$. Asimismo, a partir del nivel secundario o de educación media, la tendencia es que los que no tienen ningún rasgo étnico maya arrojan una proporción superior en un $41 \%$ a la de los jefes de familia mayas. El porcentaje de los jefes de familia no mayas con nivel de preparatoria duplica al de la población maya ( $2.3 \%$ contra $1.1 \%)$. Similar fenómeno se aprecia en el nivel universitario. Es decir, estos dos últimos niveles de educación en el grupo maya tendrían que multiplicarse por 2.5 para alcanzar los registrados en los grupos sin características mayas. En cuanto a los estudios técnicos y comerciales, se puede observar esa misma tendencia, ya que el porcentaje en los jefes de familia no mayas es el doble del de la población maya.

Este panorama nos permite apreciar que, en la desigual composición social de Chetumal, la población indígena es la que se encuentra en el plano inferior. Desigualdad que, en el caso de la educación y como asentamos antes, complica su inserción y obstaculiza su buena ubicación en el mercado de trabajo y, por tanto, impide obtener a los jefes de familia una mejor remuneración y posición en la estructura socioeconómica de la ciudad.

Diversos estudios que incluyen la educación en el análisis del mercado de trabajo, llegan a la conclusión de que esta variable resulta de vital importancia en la adscripción laboral de las personas. Por ejemplo, entre los más recientes, acerca de la heterogeneidad ocupacional en el empleo 
femenino en la ciudad de México, Rubin-Kurtzman observa que, mientras menos educacción formal tienen las mujeres, son mayoritariamente empleadas como domésticas o en trabajos de comercio informal; en tanto que, cuanto mayor es su escolaridad, trabajan en puestos que requieren más capacitación. En ese mismo sentido, la autora señala que las mujeres casadas buscan el trabajo no asalariado por razones estructurales relacionadas con la oferta y la demanda. En términos de oferta, la división del trabajo por género socialmente definido ubica el doméstico como el papel principal de las mujeres casadas. Como norma se establece que sólo cuando las mujeres casadas han asegurado la reproducción diaria de sus hogares, son libres de buscar maneras de complementar el ingreso. ${ }^{32}$ En relación con la situación que prevalece en Chetumal, y de acuerdo con las trayectorias laborales establecidas, es notoria la relación entre el empleo informal doméstico con el género femenino, y su enseñanza directa a las nuevas generaciones.

Además, como hemos visto, la población maya de Chetumal está conformada no sólo por nativos, sino también por mayas provenientes del resto de Quintana Roo, pero princi-

\footnotetext{
${ }^{32}$ Véase el trabajo de Rubin-Kurtzman, "Heterogeneidad", 1993, pp. 130-152. El trabajo de Mercedes González de la Rocha aborda la participación de las mujeres en el mercado de trabajo y confirma que éste impone limitaciones de empleo a las que sobrepasan cierta edad, a las casadas y a las que no cumplen con niveles de escolaridad de primaria completa y, a veces, secundaria; González, "Público", 1986, p. 208.
}

palmente, de los estados de Yucatán y Campeche. En ese sentido, es que resulta pertinente el análisis de las desigualdades sociales existentes dentro de la población maya, ya que es la más afectada por esta situación. El cuadro 7 explicita el fenómeno al presentar información relacionada con el analfabetismo de los mayas, según sus diferentes procedencias y tiempo de exposición urbano en la entidad.

Este cuadro nos permite ver cómo, dentro del grupo maya, la diferenciación social se encuentra, casi exclusivamente, en el sector más bajo de analfabetismo. Los mayas nativos de la entidad se caracterizan por tener el más bajo nivel de analfabetismo, mientras que este indicador es mayor en la población de nacimiento foráneo. La magnitud de esta diferencia es grande: los nativos tienen un grado de analfabetismo menor en un $34 \%$ que los de origen foráneo.

La población que siempre ha vivido en la entidad posee un grado de analfabetismo muy bajo (10.5\%), seguida por los que llegaron entre 1974 y 1983 , con $14.3 \%$. Esto nos permite ver que, dentro de la propia población maya, las desigualdades sociales dependen del tiempo de estancia en la ciudad. El segundo grupo exhibe un analfabetismo 2.4 veces mayor que el registrado por el primero. Esto se evidencia al comparar ambos grupos de migrantes. La condición migratoria de los indígenas tiene un gran peso en su inserción en el mercado de trabajo. ${ }^{33}$ Si tomamos en cuenta su

${ }^{33}$ Peter Peek y Guy Standing, en su trabajo sobre las políticas de Estado y migración, pre- 
Cuadro 7. Distribución de la población maya, según su periodo de exposición, residencia y analfabetismo (en porcentaje)

\section{Migrantes}

Migrantes radicados después de mayo de 1991

Migrantes radicados entre mayo de 1988 y abril 1991

Migrantes radicados entre mayo 1983 y abril 1998

Migrantes radicados entre 1974 y 1983

Migrantes radicados antes de 1974

Migrantes radicados en fechas desconocidas

Nativos por adopción

Nacidos fuera

Nacidos en Chetumal

Socializados fuera

Socializados en Chetumal

Total (grupo maya)
Analfabetismo
20
16.7
20
14.3
20
25
10.5
16
10
18.2
7.1
100

FUENTE: ESOYGECH, CIQRO, 1993.

posibilidad de educación y su ubicación en las actividades, llegamos a definir que, dentro de la estructura del mercado de trabajo de Chetumal, los indígenas socializados en la entidad son los que padecen menor presión económica. Ello, sin dejar de considerar su condición apremiante permanentemente.

Sin duda que el establecimiento ahí de una política social y educativa, dirigida a la disminución de las desigualdades, tendría que considerar a la población maya, según su arribo a la

sentan un sugestivo análisis de los modelos dualista y neoclásico y sus perspectivas analíticas. En especial refieren sus posiciones en torno a las explicaciones que se le han dado al fenómeno migratorio, como consecuencia de la estructura, como una decisión individual, y como un aspecto positivo, pues proporciona mano de obra a la industrialización; Peek y Standing, "Políticas", 1989, pp. 11-15. ciudad: la que se estableció antes de 1974, la que llegó entre 1983 y 1988, y la que se estableció entre los dos últimos años, sin olvidar la presencia de la población maya nativa de Chetumal.

DESIGUALDAD SOCIAL: LOS MAYAS

Y LOS NO MAYAS

Para analizar las desigualdades entre los grupos de población de Chetumal, recurrimos a los parámetros de bienestar. Los principales indicadores en este sentido son los salarios, las ramas de empleo y el tipo de ocupación. Estos rubros se analizan a través de la comparación de los más favorecidos con los menos favorecidos. Lo anterior facilitó la identificación de los movimientos sociales que producen marginalidad y pobreza. 
En primer plano, encontramos que en un porcentaje alto los migrantes que arribaron a esta capital se han integrado a la agricultura. Ello parece indicar la relación entre su trabajo anterior y su escasa capacidad para insertarse en el mercado del sector terciario. Los migrantes que llegaron en distintos periodos muestran, como se ha señalado que, además del tiempo, lo que determina su tipo de trabajo es su historia laboral; es decir, si su empleo anterior es del sector primario, en Chetumal será esta actividad una de las que primordialmente se hallará en los márgenes de una economía caracterizada por la amplitud del sector terciario, y cuyas características son mayor pobreza y menor nivel de educación formal.

Cuando abordamos el ingreso de la población indígena como fuerza de trabajo en Chetumal, consideramos estas condiciones de reproducción laboral. Diego Iturralde menciona que estas formas de inserción en la economía se caracterizan, entre otras cosas, por el mantenimiento de la relación campo-ciudad como una línea de transmisión bidireccional, la cual produce, de una manera progresiva, las formas indígenas de reproducción de la fuerza de trabajo; es decir, se encuentran dentro de la dinámica laboral nacional y tienen su efecto en la organización de su vida cotidiana en las ciudades. ${ }^{34}$ En Chetumal es notoria una continuidad de formas de economía agrícola en los migrantes, ya que los resultados que obtuvimos refieren que el $9.5 \%$ de los jefes

${ }^{34}$ Véase Iturralde, "Pueblos", 1991, p. 36. mayas se encuentra laborando en actividades agrícolas, en cambio, de los jefes no mayas, ninguno trabaja en la agricultura. Los ingresos de los mayas, por tanto, son insuficientes para su población y parecen no permitir la reproducción adecuada de las unidades domésticas. ${ }^{35}$

Si tomamos en cuenta que, las ramas de actividad que permiten mejores salarios son la administración pública y los bancos, vemos que la participación de los mayas en tales instancias es relativamente baja: de un $29 \%$ en la administración y de un 9.5\% en los bancos. Los trabajadores no mayas con mayor socialización, es evidente que se integran a estos mismos servicios con mayor capacidad. En la administración pública tenemos a $41 \%$ de su población y en bancos al 14.5\%; en ambos casos se rebasa a la población con características indígenas. Por su parte, las ramas informales que concentran población con bajos salarios son el comercio al menudeo y los servicios domésticos. En ellas, la población indígena maya ocupa el mayor porcentaje de participación; esto manifiesta, entre otras cosas, que

\footnotetext{
${ }^{35}$ De manera general, sobre el proceso de urbanización y sus consecuencias en México, puede consultarse el trabajo de Claudio Stern, quien analiza que el "papel de la migración rural-urbana fue significativo, tanto desde el punto de vista de la urbanización global como en cuanto a la expansión de las grandes ciudades. El desarrollo del industrialismo en una nación agraria tiene que ver con la translerencia de mano de obra de las actividades primarias a las secundarias y terciarias, e implica la movilidad geográfica de la población clesde pueblos dispersos hacia áreas urbanas"; Stern, "Industrialización", 1986, pp. 198-204.
} 
su capacidad de competencia en el mercado local se ve reducida a estas dos actividades. En el comercio al menudeo tenemos a un $\mathbf{1 6 . 2 \%}$ de población indígena y un $9 \%$ de población no indígena, es decir, que por cada 100 no mayas, existen 20 mayas que trabajan en esta rama. En el mismo sentido se muestra que, de cada 100 personas no mayas, hay 40 mayas que trabajan en los servicios domésticos.

Al hablar de categorías ocupacionales distinguimos dos niveles: las favorables, como las de empresarios y empleados; y las desfavorables o marginales, como las de los peones y los trabajadores por cuenta propia. Los salarios varían entre medios y altos para los primeros e insuficientes y bajos para los segundos. En relación. con los empresarios, tenemos que $5.4 \%$ son mayas en comparación con $10.9 \%$ de no mayas. Esto representa que, por cada 100 empresarios no mayas, existen 49 que son mayas. Los empleados arrojan un $75 \%$ de no mayas con un $67 \%$ de mayas, esto equivale a que, de cada 100 empleados no mayas hay 90 mayas, y aunque en este rubro no es grande la diferencia, podemos indicar que la suma de todas las ramas es lo que determina su posición desfavorable de manera constante.

De las categorías marginales o informales, como son las de los peones y los trabajadores por cuenta propia, tenemos que la población maya continúa en desventaja. En el trabajo de peón hay más de $4 \%$ de mayas, lo que en comparación con el de no mayas es alto, dado que éstos, en este tipo de empleo, no rebasan ni siquiera el
1\%. Entre los trabajadores por cuenta propia, tenemos el mismo esquema, es decir que los mayas tienen un $21.6 \%$, mientras que los no mayas solamente cuentan con un $12 \%$ de su población ocupada en esta categoría.

Además, la información acerca de los salarios refleja en mucho las posibilidades de la población de acceder a los servicios y a una vida de bienestar. Los salarios de subsistencia no existen entre la población no maya, mientras que en la población con características mayas alcanza un $4 \%$. En los salarios con niveles de subsistencia a bajos, los mayas tienen la mayoría; es un $57 \%$ de su población la que recibe este monto. Por su parte, la población no maya representa en ellos sólo un $37 \%$. A partir de los niveles de buenos ingresos, la tendencia se invierte, dado que en los salarios medios y medianamente altos hay mayor representatividad de población no maya: por cada 100 mayas hay registrados 164 no mayas.

Dentro del mercado de trabajo existen limitaciones estructurales para los grupos que realizan actividades por cuenta propia. En principio, observamos que, de cada cuatro mayas ocupados, uno se dedica a actividades por cuenta propia. Esta proporción es significativa para entender que siempre existe una desventaja notable entre los dos grupos de población: los mayas y los no mayas. En este mismo desequilibrio, podemos citar que, en el interior del grupo maya, existen diferencias determinadas por el tiempo de residencia en la ciudad: por ejemplo, los mayas con fecha de arribo más reciente, en 1991, tienen menos posi- 
bilidades de insertarse en el mercado con salarios favorables, por lo que quedan entre los salarios de subsistencia y muy bajos. En relación con las ramas de ocupación los mayas se encuentran en el comercio al menudeo y en los servicios domésticos y, para terminar de reafirmar lo anterior, ninguno tiene acceso a puestos en el sector público ni a ramas formales.

Las condiciones de esta fuerza laboral nos obligan a reflexionar sobre la distribución desigual de la riqueza y sobre la continuidad de modelos económicos que refuerzan la marginación de la población indígena. La modernidad los coloca en los márgenes que los grupos dominantes definen; lo étnico queda relegado a un reconocimiento aparente, no real, como lo revela al menos la estructura de la ocupación.

\section{BIBLIOGRAFÍA}

-Arizpe, Lourcles, Migración, etnicismo y cambio económico. Un estudio sobre migrantes campesinos a la ciudad de Mé. xico, El Colegio de México, México, 1978.

-Arnaiz Borne Stella Maris, "El turismo y los cambios en la globalización" en Alfredo César Dachary y otros (comps.), Quintana Roo: los retos del fin del siglo, CIQRO, Quintana Roo, México, 1992.

-Baños Ramírez, Othón, "Reconfiguración rural-urbana en la zona henequenera de Yucatán", Estudios Sociológicos, El Colegio de México, núm. 32, 1993, México.

-Barrera Vázquez, Alfredo, Diccionario Maya Cordemex, Ediciones Cordemex, Mérida, 1980.

-Barth, Fredrik, "Introducción" en Fre- derich Barth (comp.), Los grupos étnicos y sus fronteras, FCE, México, 1976.

-Bonfil Batalla, Guillermo, México profundo. Una civilización negada, Grijalbo, México, 1994.

-Bracamonte y Sosa, Pedro, La mmoria en claustrada. Historia indigena de Yucatán, CIENSAS/INI, México, 1994.

-Bueno, Carmen, "Migración indígena a la construcción de vivienda en la ciudad de México" Nueva Antropología, núm. 46, 1994, México.

-Cardoso de Oliveira, Roberto, Etnicidad y estructura social, CIESAS, México, 1992.

-César Dachary, Alfredo, Daniel Navarro y Stella Maris Arnaiz (comps.), Quintana Roo: los retos del fin de siglo, CIQRO, México, 1992.

-Cohen, Ronald, "Ethnicity: problem and focus in anthropology", Annual Review of Antbropology, núm. 7, 1978.

-Contreras Jesús, La cara india, la cruz del 92. Identidad étnica y movimientos indios, Revolución, Madrid, 1988.

-Daltabuit Godás, Magalí, Mujeres mayas. Trabajo nutrición y fecundidad, Litoarte/Instituto de Investigaciones Antropológicas-UNAM, México, 1992.

-De Teresa, Ana Paula, "La encuesta genealógica: una propuesta para el análisis de la reproducción de la economía campesina", Nueva Antropología, núm. 39, 1991, México.

-De Vos, George, "Social stratification and ethnic pluralism: an overview from the perspective of psichological anthropology", Revista Race, Institute of Race Relation, Oxford University Pres, núm. 4, 1978 , Londres.

-Díaz Polanco, Héctor, Autonomía regional. La autodeterminación de los pueblos indios, Siglo XXI, México, 1991.

-Escobar Latapí, Agustín, Con el sudor de la frente, mercado de trabajo y clase obrera en Guadalajara,El Colegio de Jalisco, México, 1986. 
-Patrones de organización social en el mercado de trabajo manual de Guadalajara" en Guillermo De la Peña, y Agustín Escobar Latapí (comps.), Cambio regional, mercado de trabajo y vida obrera, El Colegio de Jalisco, México, 1986.

-Gabayet Ortega, Luisa, "Diferenciación. social y formación de clase obrera: análisis comparativo de tres casos jaliscienses" en Guillermo De la Peña, y Agustín Escobar Latapí (comps.), Cambio Regional, mercado de trabajo y vida obrera en Jalisco, E1 Colegio de Jalisco, México, 1986.

- García, Brígida, Desarrollo económico $y$ absorción de fuerza de trabajo en Mé. $x i c o$, El Colegio de México, México, 1988.

din te Oumberto Muñoz y Orlandina drabajadores en la ciudad de México, El Colegio de México/UnAM, México, 1988.

- y Orlandina de Oliveira, "Trabajo y familia en la investigación sociodemográfica de México" en Francisco Alba y Gustavo Cabrera (comps.), La población en el desarrollo contemporáneo de México, El Colegio de México, México, 1994.

-García Canclini, Néstor (coord.), El consumo cultural en México, Nueva Imagen, México, 1993.

-González de la Rocha, Mercedes, "Lo público y lo privado: el grupo doméstico frente al mercado de trabajo urbano" en Guillermo De 1a Peña, y Agustín Escobar Latapí (comps.), Cambio regional, merca. do de trabajo y vida obrera en Jalisco, El Colegio de Jalisco, México, 1986.

-Hamel, Enrique, "Derechos lingüísticos" Nueva Antropología, núm. 44, 1993, México.

-Hervik, Peter, "Social categories in Yucatan", Working Paper, Anthropology, University of Copenhagen, núm. 14, julio, 1994.

-Hostettler, Ueli, "Transformaciones en el medio rural: unidad doméstica y estratificación socioeconómica en el municipio de Felipe Carrillo Puerto, Quintana Roo", ponencia presentada en el $2^{\circ}$ Congreso Internacional de Mayistas, Mérida, Yucatán, 24 al 29 de agosto, 1992.

-Instituto Nacional de Estadísticas y Censos, InEgI, Quintana Roo. Perfil sociodemográfico. INEGI, México, 1990.

-Iturralde G., Diego A., "Los pueblos indios como nuevos sujetos sociales en los estados latinoamericanos", Nueva Antropología, núm. 39, 1991, México.

-Ligorred, Francesc, Lenguas indigenas de México y Centroamérica, MAPFRB, Madrid, 1992.

Yucatán" Por Esto!, Secc. Unicornio, Mé rida, Yucatán, 12 de junio, 1994.

-Martí, Fernando, Cancún, fantasía de banqueros, Uno, México, 1985.

-Medina, Andrés, "La identidad etnica: turbulencias de una definición" en Leticia I. Méndez y Mercado (comp.), I Seminario sobre identidad; Instituto de Investigaciones Antropológicas-UNAM, México, 1992.

-Mendoza Ramírez, Martha, "El impacto de la colonización dirigida en la frontera sur. Análisis de la ribera del río Hondo en Quintana Roo, 1970-1980", Secuencia, Instituto Mora, núm. 37, México, 1997.

-Peek, Peter y Guy Standing, "Las políticas de Estado y la migración de la mano de obra" en Peter Peek y Guy Standing (comps.), Políticas de Estado y migración. Estudios sobre América Latina y el Caribe, El Colegio de México, México, 1989.

-Pérez Sáinz, Juan Pablo, Manuela Camus y Santiago Bastos, Todito, todito es trabajo. Indígenas y empleo en ciudad Guatemala, FLACSO, Guatemala, 1992.

- "Trayectorias laborales y constitución de identidades: trabajadores indígenas en la ciudad de Guatemala", $E s$ tudios Sociológicos, El Colegio de México, núm. 31, 1993, México.

-Pfeiler, Barbara, "La lealtad lingüística del indígena maya yucateco. Validación de 
la prueba de matched-guise", Revista de la Asociación Mexicana de Lingüística Aplicada, Centro de Enseñanza de Lenguas Extranjeras-UNAM, núm. 17, México, 1993.

-Ramírez, Daniel y Ricardo Yocelevzky, Política y población en América Latina. Revisión de los aportes de Pispal, PISPAL/ El Colegio de México, México, 1986.

-Re Cruż, Alicia, "Lo sagrado y lo profano de la identidad maya entre los emigrantes en Yucatán", Nueva Antropología, núm. 46, 1996, México.

-Rubin-Kurtzman, Jane R., "Heterogeneidad ocupacional del empleo femenino en la ciudad de México, 1970", Estudios Demográficos y Urbanos, vol. 22, núm. 1, El Colegio de México, 1993, México.
-Stavenhagen, Rodolfo, "Notas sobre la cuestión étnica", Estudios Sociológicos, El Colegio de México, núm. 4, 1984, México.

-Stern, Claudio, "La industrialización y la migración de la mano de obra", en Peter Peek y Guy Standing (comps.), Politicas de Estado y migración. Estudios sobre América Latina y el Caribe, El Colegio de México, México, 1986.

-Terán, Silvia y Christian Rasmussen, $L a$ milpa de los mayas, Gobierno del Estado de Yucatán, México, 1994.

-Warman, Arturo, "Estrategias de sobrevivencia de los campesinos mayas", Cuaderno de Investigación Social, Instituto de Investigaciones Sociales-UNAM, núm. 13, 1985, México. 


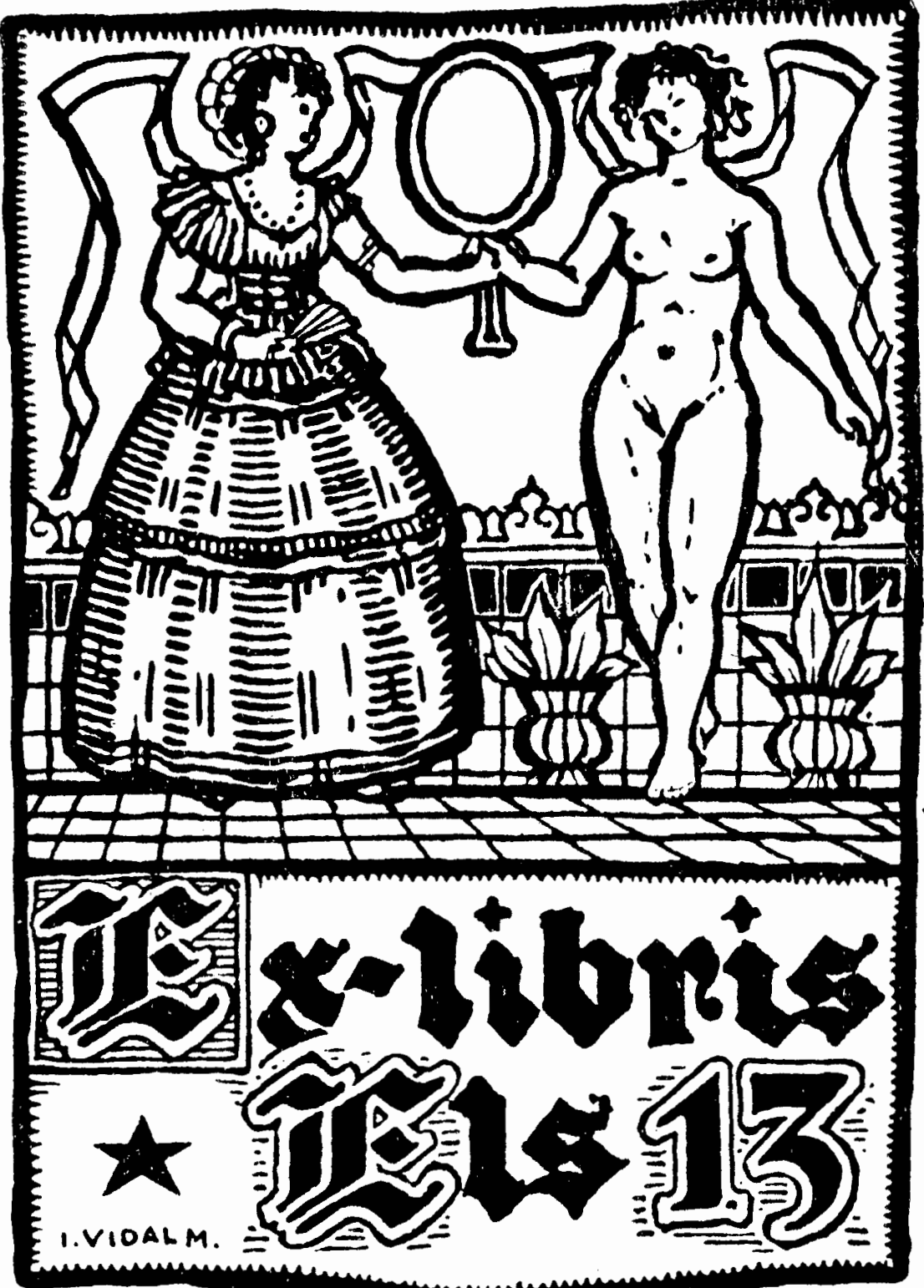

